In patients liable to spontaneous urticarial weals ${ }^{12}$ the ease with which dermographism could be elicited depended on their emotional state, a feeling of being wronged or injured under circumstances which precluded action on their part being most favourable. Trauma to one arm led to a fall in the tonus of the small skin vessels on both sides, but a feigned blow caused a fall on the threatened side alone.

If a cut sensory nerve is stimulated electrically impulses pass down it antidromically (the "wrong way") and vasodilatation results in the skin. The flare and oedema round a site of minor injury to the skin are mediated by the "axon reflex." Afferent impulses are believed to pass up branches of a sensory nerve, but, before reaching the posterior root ganglion, to turn down other branches, so causing dilatation of blood vessels in the skin by the release of adenosine triphosphate. ${ }^{13}$ Local blistering ${ }^{1511}$ can be caused by suggesting pain and burning to a hypnotized subject despite only tapping the skin lightly with a pencil. F. A. Pattie ${ }^{14}$ decided that such blistering could not be mediated by sympathetic nerve fibres but only by an efferent route from brain and spinal cord to posterior root ganglion with subsequent flow of antidromic impulses. It has sometimes been argued that such impulses influence the distribution of herpes zoster vesicles. A. Rosenblueth and W. B. Cannon ${ }^{1.5}$ concluded that some vasodilator impulses to the skin and viscera travelled by this route in emotionally disturbed and struggling dogs, and also when they carried out direct electrical stimulation of part of the medulla oblongata.

The clinician must respect his disputing physiological colleagues, ${ }^{16}$ but if such a nervous mechanism exists there are ample precedents for supposing it to be supplemented by humoral ones. Tissue permeability can be altered by adrenocortical hormones, the secretion of which is controlled by the anterior pituitary and hence governed by the hypothalamus and all nervous mechanisms working thereon. Further research is needed into the central factors affecting inflammatory reactions, the importance of which is not confined to disorders of allergy. Meanwhile there would seem to be sound theoretical support for treating a minor injury by "kissing it better."

\section{Achalasia of the Cardia}

The disorder of swallowing often called "achalasia of the cardia" has been the cause of much confusion in the past because it has masqueraded under various names. In addition to achalasia they have included cardiospasm and mega-

1 Uliman, M., Amer. F. Psychiat., 1947, 103, 828.

2 Moody, R. L., Lancet, 1946, 2, 934.

- in Modern Trends in Psychological Medicine, p. 286, 1948. Hadfield,

- Hadfield, J. A., Lancet, 1917, 2, 268.

- ibid., 1920, 2, 68.

- Black, S., Brit. med. F., 1963, 1, 925.

- Ibid ibid., 1963, 1, 1 ,

- Ibid., 1963, 1, 968.

- Black, S., Humphrey, J. H., and Niven, J. S. F., ibid., 1963, 1, 1649. Maher-Loughnan, G. P., Macdonald, N., Mason, A. A., and Fry, L., ibid., 1962, 2, 371 .

1 Chapman, L. F., Goodell, H., and Wolf, H. G., Arch. Neurol. (Chic.), $1959,1,557$

12 Graham, D. T., and Wolf, S., F. Amer. med. Ass., 1950, 143, 1396.

13 Holton, P., f. Physiol. (Lond.), 1959, 145, 494.

14 Pattie, F. A., 7. abnorm. soc. Psychol., 1941, 36, 62.

15 Rosenblueth, A., and Cannon, W. B., Amer. F. Physiol., 1934, 108, 599.

10 Folkow, B., Ström, G., and Uvnäs, B., Acta physiol. scand., 1950, 21, 145. oesophagus. Its pathology has not been elucidated; it has been identified with various radiological appearances; and its treatment has been a matter for debate.

The disorder is rather uncommon, and since physicians, surgeons, and otolaryngologists have all shared in its treatment few individuals have had extensive personal experience of the condition and still less the opportunity to follow the effects of treatment over a long time. As Mr. N. R. Barrett points out in his paper at page 1135 of the B.M.F. this week, the achalasia is progressive and the effects are felt for a very long time, for it does not usually cause death at an early age. The radiological appearances in the established case are those of a dilated oesophagus with a thickened hypertrophied wall ending in a smooth tapering obstruction at the oesophagogastric junction. This appearance has focused attention on the cardia as the seat of the trouble. But this situation bears no resemblance to the sort of obstruction that occurs for example at the pylorus, for here the dilatation and hypertrophy of the stomach are associated with increased peristalsis which partially overcomes the obstruction; whereas in achalasia of the cardia oesophageal peristalsis is soon completely lost. It would be difficult to see why a muscular tube should become hypertrophied if in fact it was not doing anything to overcome the obstruction. A. F. Hurst and A. W. Rake ${ }^{1}$ noted the degeneration of the nerve plexus in the oesophageal wall and believed that this resulted in a failure of the relaxation of the cardia which normally occurs with swallowing. They therefore coined the name " achalasia of the cardia." Here again attention was focused on the cardia, the more so because it was found that stretching the cardia had a beneficial effect on symptoms. Hurst devised and used his mercury bougie; the abdominal surgeons performed gastrotomy and stretched the cardia with their fingers; the otolaryngologists devised instruments to be passed through the oesophagoscope, and of these the best and the most humane is the Negus hydrostatic bag. The more enterprising surgeons anastomosed the dilated lower end of the oesophagus to the fundus of the stomach. This operation, which had too long a vogue on the continent of Europe and in the United States of America, invariably led to peptic ulceration of the oesophagus and all its complications.

On 14 April 1913 E. Heller, ${ }^{2}$ in Leipzig, set out to do a cardioplasty with oesophago-gastric anastomosis on a patient, and after he had mobilized the oesophagus and pulled it down into the abdomen he lost heart. The anastomosis looked too difficult and the oesophagus, uncovered with peritoneum, looked too unreliable. So he decided to do a myotomy on the basis of the good results of such an operation at the pylorus. He divided the muscle layers down to the mucosa at the front and the back of the oesophagus and stomach by incisions $8 \mathrm{~cm}$. long. The immediate success of this operation impressed Heller but failed to impress many others, and it took a long time in Great Britain, and still longer in America, for the full value of the operation to be recognized. Two things have happened more recently to alter our ideas about the pathology of the condition, though Heller's myotomy still remains the standard treatment. The first of these is the discovery in South America, ${ }^{3}$ where the condition is frequently associated with megacolon, of the parasites of Trypanosoma cruzi in the oesophageal wall. The toxin liberated by their death causes degeneration of the cells of

\footnotetext{
${ }^{1}$ Hurst, A. F., and Rake, A. W., Quart. F. Med., 1930, 23, 491.

Heller, E., Mitt. Grenzgeb. Med. Chir., 19i4, 27, 141.

Koberle, F., Gastroenterology, 1958, 34, 460

4 Johnstone, A. S., Brit. F. Radiol., 1960, 33, 723.
} 
the nerve plexuses. This indicates the basic pathological change, though the toxin in places where Chagas's disease does not occur must obviously be a different one. The second has been the radiological diagnosis of the condition, particularly by A. S. Johnstone ${ }^{4}$ in Great Britain, at a very early stage before any dilatation or hypertrophy has occurred, when the appearances are of completely dissociated movements without any propulsive action. The condition is now seen, therefore, to be a disorder of the body of the oesophagus, and the failure of the cardia to relax is just one expression of the degeneration of the nerve plexuses. Heller's operation merely diminishes the hydrostatic pressure that is necessary to force food through to the stomach.

Any surgeon who has seen a sufficient number of cases of achalasia of the cardia, investigated them by radiology, oesophagoscopy, and thoracotomy, and then followed their progress over the years will be in substantial agreement with the descriptions, the treatment, and the conclusions which Barrett provides in his present paper.

\section{Maternal Rubella and Pulmonary Arterial Stenoses}

Since the original clinical observation of N. M. Gregg ${ }^{1}$ it has become well established that rubella in early pregnancy may lead to congenital heart disease in the infant. The abnormality most frequently found is a patent ductus arteriosus, but recently $M$. Campbell ${ }^{2}$ has pointed out that a wide variety of cardiac malformations may be produced. These include ventricular and atrial septal defects, stenosis of the pulmonary and aortic valves, Fallot's tetralogy, coarctation of the aorta, tricuspid atresia, and transposition of the great vessels. In the same year as Campbell's report, $H$. Arvidsson and his colleagues described localized stenosis of the pulmonary arteries in three children whose mothers had rubella during pregnancy. ${ }^{3}$ The same association had been noted incidentally some four years earlier by $A$. Gyllenswärd and his co-workers $^{4}$ and C. B. Williams and his colleagues. ${ }^{5}$ More recently $R$. D. Rowe has confirmed the relation between maternal rubella and stenosis of the pulmonary artery in the offspring. ${ }^{6}$

In 1959 there was an epidemic of rubella in New Zealand ${ }^{7}$ and 31 infants born with congenital heart disease associated with the disease were investigated at the Green Lane Hospital in Auckland. No fewer than seven of them were found to have stenosis of the pulmonary arteries. Four older children with the same condition and a history of maternal rubella had previously been studied in Auckland, and these 11 patients form the subject of Rowe's report. The rash of rubella had usually occurred during the fifth week of pregnancy. The average birth weight of the affected infants was low and most of them had deafness, bilateral cataracts,

1 Gregg, N. M., Trans. ophthal. Soc. Aust., 1941, 3, 35.

2 Campbell, M., Brit. med. F., 1961, 1, 691.

Arvidsson, H., Carlsson, E., Hartmann, A., Tsifutis, A., and Crawford, C., Acta radiol., 1961, 56, 466.

- Gyllenswärd, A., Lodin, H., Lundberg, A., and Möller, T., Pediatrics, 1957, 19, 399.

s Williams, C. B., Lange, R. L., and Hecht, H. H., Circulation, 1957, 16, 195

- Rowe, R. D., Pediatrics, 1963, 32, 180

'Liggins, G. C., and Phillips, L. I., Brit. med. F., 1963, 1, 711.

Wagenvoort, C. A., Heath, D., and Edwards, J. E., in Pathology of the Pulmonary Vasculature, 1964. Charles C. Thomas, Springfield, Illinois.

C or both. The most useful clinical aid to diagnosis of the condition was found to be the murmur produced by the arterial obstruction. This is usually systolic but more rarely continuous, being loudest at the pulmonary area but heard well on both sides of the chest. In mild cases the murmur may be slight, but its characteristic radiation to both sides of the chest is still present.

Localized pulmonary arterial stenosis may appear in one of three main forms. ${ }^{8}$ Firstly, there may be isolated or multiple stenoses of the pulmonary arteries themselves. Secondly, there may be involvement of the bifurcation of the pulmonary trunk, the so-called " coarctation of the pulmonary artery." Thirdly, stenosis may be due to a membrane situated immediately above the pulmonary valve. In all of Rowe's patients the stenosis affected the pulmonary arteries themselves. Their type, degree, and extent were shown by cardiac catheterization and selective angiocardiography. The stenosis was mild in seven but moderately severe in the remaining four children; it was bilateral in nine. In five cases the obstruction was central and involved the origins of the main branches of the pulmonary arteries, but in three it was situated more peripherally. In the remaining cases it was not possible to demonstrate the precise location of the obstruction. Five of the patients had other congenital heart lesions as well. All 11 patients have survived, and, as in most reported examples of this disease, pathological studies of the affected arteries have not been made. It has been found, however, that usually such stenoses are due to fibrosis of the intima of the artery. ${ }^{8}$

Progressive symptoms from this disease in childhood are rare, but if the stenoses are multiple and situated peripherally the prognosis must be assumed to be poor. Surgery may have something to offer in treatment of lesions in the major pulmonary arteries and in the region of the pulmonary valve.

Clearly this new report establishes that maternal rubella plays a part in causing pulmonary arterial stenosis. If systolic or continuous murmurs, which radiate into both sides of the chest, are heard on listening to an infant's heart, and there is a history of maternal rubella, a search for this condition is indicated. Similarly, if a systolic murmur is still heard after surgical closure of a patent ductus arteriosus in such infants the possibility of pulmonary arterial stenosis must be borne in mind.

\section{Skin Reticuloses}

Rare diseases are of interest to the specialist and to patients who suffer from them. Sometimes the condition may be so uncommon and its course so protracted that even the specialist has not enough personal experience to answer accurately the patient's questions, particularly about prognosis. This is especially true of the ill-defined group labelled the reticuloses and notably those which are limited wholly or mostly to the skin. These vary from the benign patchy scaling rash of parapsoriasis en plaques, which looks something like psoriasis but persists indefinitely, to frankly malignant diseases such as lymphosarcoma and reticulum-cell sarcoma. In between lies that peculiar condition mycosis fungoides, which histologically closely resembles Hodgkin's disease and which may run a benign course for years before developing into wide-

\footnotetext{
1 Lapière, M. S., Arch. belges Derm., 1948, 4, 40

2 Samman, P. D., Brit. f. Derm., 1964, 76, 1

Szur, L., ibid., 1964, 76, 10.
} 